\title{
Identification and analysis of noise sources in the Noor-Abad gas compressor station, Iran
}

\author{
Nader Mohammadi $^{1 *}$, Kami Mohammadi ${ }^{2}$ \\ ${ }^{1}$ Department of Mechanical Engineering, Islamic Azad University, Parand Branch, Tehran, Iran \\ ${ }^{2}$ Department of Civil and Environmental Engineering, Georgia Institute of Technology, Atlanta, USA \\ *Corresponding author E-mail: nmohamady@ut.ac.ir
}

Copyright ( $\odot 2015$ Nader Mohammadi, Kami Mohammadi. This is an open access article distributed under the Creative Commons Attribution License, which permits unrestricted use, distribution, and reproduction in any medium, provided the original work is properly cited.

\begin{abstract}
The objective of this study is to identify the sources of acoustic noise (noise pollution) in the Noor-Abad gas compressor station and then to prioritize the station equipment based on noise pollution. First, the key locations inside the station as well as in the surrounding residential area, aka the study area, are determined for the measurement of sound pressure level. Then, the sound pressure level is measured at those points, and the related noise map is produced. Based on the noise map, the noise condition in the study area is evaluated by comparing the measured acoustic parameters with allowable standard values. Dangerous regions and critical points are thus identified. The major noise sources consist of main blowdown, units' blowdowns, scrubbers, and turbo-compressors. The sound pressure level of main blowdown is measured at two intervals from its position: $80 \mathrm{~m}$ inside the station and $600 \mathrm{~m}$ outside the station (at the edge of the surrounding residential area). Also, the sound pressure level for a unit blowdown and a scrubber is measured at respectively $25 \mathrm{~m}$ and $40 \mathrm{~m}$ from their positions. Finally, the station equipment is prioritized based on noise pollution. The analysis of measurement results showed that the main noise sources are, respectively, the station main blowdown, units' scrubbers, units' blowdowns, turbo-compressors, and gas pipelines.
\end{abstract}

Keywords: Gas Compressor Station; Industrial Noise Source; Noise Measurement; Noise Pollution.

\section{Introduction}

In many countries, nowadays, factories and industrial stations are located inside the metropolises and close to residential areas. One of the major difficulties associated with this trend is the increasing noise pollution in these areas. Therefore, many substantial researches and studies have been performed in order to remove or reduce this pollution. Gas compressor stations are among these industrial stations. High pressure outlet pipes (blowdowns), from which high pressure gas is discharged, are one of the main acoustic noise sources in these stations.

Noor-Abad gas compressor station, $5 \mathrm{~km}$ from Noor-Abad city, is located in zone 5, on the nationwide gas transfer lines 2 and 3. This station, which is one of the most important gas compressor stations in the nation, is very close to the residential area. Therefore, the resulting noise pollution could be very substantial issue. The station's equipment such as turbo-compressors, blowdowns, scrubbers, cooling fans and valves have largely increased the sound pressure levels above the allowable limits both inside the station and neighboring residential area. The transmitted noise to the residential area is a threat to the physical and mental health of its residents and a reduction in their level of tranquility and may lead to their dissatisfaction. In addition to causing exhaustion and ear injuries, sound levels above allowable range may be a potential reason for one's poor performance at work, sleep disorder and communication problems. It also agitates the mental and physiological reactions of an individual which in turns leads to negative social impacts. Therefore, the main goal of this study is to recognize the sources of noise pollution in this station and to prioritize them based on generating noise pollution.

In the first phase of this study, site specific data along with other information extracted from similar studies, texts, articles and relevant standards are collected to form the bases of study. These bases consist of the procedure, the map of 
station and surrounding region (including the residential area), the main sources of noise pollution in the compressor station, acoustic parameters that need to be measured, appropriate methods and equipment for measurement, and allowable noise level and permissible exposure time. In the second phase, the key points for measuring the sound pressure level both inside the station and in the residential area are determined. Then, using appropriate measuring equipment, the sound pressure level is measured at specified points. In addition, the main noise sources in the station are identified and their noise levels are measured at specified points. The main sources of noise pollution include blowdowns, compressors, turbines, valves, and fans. The results obtained from field measurements are analyzed and the sound map for the study area is prepared. Comparing the measured acoustic parameters with allowable values of standards, dangerous zones and critical point of noise pollution are defined. Also, the pollution level of different sources is determined and the equipment of station is classified based on noise pollution level.

\section{Field information of Noor-Abad gas compressor station}

Noor-Abad gas compressor station, $5 \mathrm{Km}$ from Noor-Abad city, is located in zone 5, on the nationwide gas transfer lines 2 and 3 and is among the important gas compressor stations in the country. This station has 4 turbo-compressor units in line 2 and 4 in line 3. Due to its proximity to residential area, the resulting noise pollution turns into a serious problem that should be investigated. The preliminary studies, carried out before the field tests, clearly showed that the main noise pollution sources are mostly related to the line 2 , equipment are relatively older.

The natural acoustic barriers, such as the rock hills near the station and the surrounding residential area (working as sound reflector), increase the sound pressure level both inside the station and in the surrounding residential area. It is possible to minimize the effects of this sound reflector through planting bushes and trees on the hills which act as acoustic absorbers.

The technical structure of gas compressor stations shows that the noise caused by the station equipment and machinery is of two permanent and discontinuous natures; the permanent noise is due to the non-stop operation of the turbocompressors and all related elements such as the gas pipelines, cooling fans and the turbines' air inlets and outlets. On the other hand, the necessity of gas discharge by the units' blowdowns and scrubbers, which may happen several times during a day (when the unit starts- stops or in case of defect), generates a discontinuous noise field that extends about 12 minutes every time. Field investigations show that the noise generated by the units' blowdowns is more than that of the units' turbo-compressors. The discharge of the main blowdown, as the main source of noise, which becomes necessary during the station shutdown, overhaul, or pigment operations in the nationwide gas transfer lines, is quite important. Usually, the main blowdown is discharged every 6-12 months. The jet noise caused by the discharge of the main and units' blowdowns makes the acoustic field of the station much more complex in the surrounding residential areas.

Field investigations show that the main noise sources in Noor-Abad gas compressor station include the units' turbocompressors, the turbines' air inlets and outlets, the main blowdown ( 1 for every line), the units' blowdowns and scrubbers, cooling fans, valves, bends, and piping that transfer gas from/to the turbo-compressors.

\section{Measurement}

The measurement process of the sound pressure level has been designed based on ISO 9612 standard which includes the specification and location of measurement equipment, measurement intervals, and acoustic quantities to be measured.

\subsection{Measurement equipment and their technical adjustments}

\subsubsection{Sound level meter}

The measurement device is a B\&K 2260 sound level meter; the Precision Type with $1 \mathrm{~dB}$ accuracy. The sound level meter meets the requirements of the IEC 6065 standard for measuring the sound levels. Also, its octave and 1/3 octaveband filters meet the requirements of IEC 61260 standard. In addition to frequency signal analysis, the meter is also capable of processing and computing many of required absolute and statistical acoustic quantities such as $\mathrm{L}_{\text {peak }}, \mathrm{L}_{\mathrm{eq}}, \mathrm{L}_{\text {max }}$, and $\mathrm{L}_{\text {min }}$ in different weighted networks. For measurement of noise pollution and codification of controlling strategies, A-weighted and C-weighted networks would be sufficient. The A-weighted network is developed as a set of filters in sound level meters that simulate the frequency sensitivity of the human hearing mechanism. Because human response is normally the reason for an environmental noise evaluation, A-weighted decibels are usually the units of choice. The $\mathrm{C}$-weighted network is used to carry out professional evaluations regarding noise control and hearing protection. Considering the discontinuous nature of the measured sound level and the related rapid variations, the meter has both the weighted frequency and appropriate time networks. The fast, slow, and impulse are the 3 available common types of time weighting networks. The impulse and fast types, with time constants of respectively 35 and 135 milliseconds, is specifically used in measuring the noise caused by vehicles traffic, or in analyzing the sound 
pollution caused by such instant phenomena as an explosion. The slow type, with a time constant of about 1 second, on the other hand, is appropriate for measuring sound fields with occurrence continuities of more than a few seconds such as the ones working in Noor-Abad gas compressor station.

\subsubsection{Calibrator and microphone}

Sound calibrators, which used to calibrate sound measurement devices, should meet the requirements of IEC 942 class 2 Standard. The microphone calibrator is a B\&K type 4230 sound level calibrator which meets the requirements of IEC 942 class 2 Standard. (The calibration of the microphone and the measuring device has been done prior to the measurements)- This is trivial. The microphone used in the measurement is a B\&K type 4950 which meets the requirements of all the related standards. Since measurements are taken in outdoor, wind blow can affect the measurement process and cause error, especially in high frequency measurements; therefore, a polyurethane spherical windscreen is used, that covers the microphone. To fix the measuring device at a constant height, a tripod, according to ISO 1120 standard, is used that stabilizes the microphone position at $1.55 \pm 0.075 \mathrm{~m}$ above the ground surface (see Fig. 1).

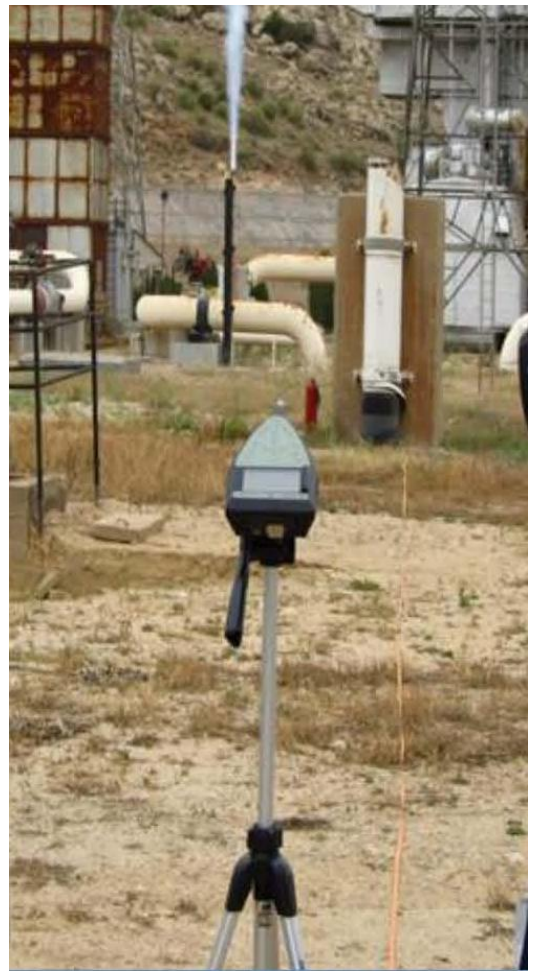

Fig. 1: The Photograph of the Sound Level Meter Used For the Measurements.

Considering field investigations and station's acoustic conditions, the measurements have been taken in line 2 and included the following items:

1) The sound level of the main blowdown

2) The sound level of the units' blowdowns

3) The sound level of the units' scrubbers

4) The sound level inside the control rooms

5) The sound field around the station

\section{Results}

\subsection{Measuring the sound level of the main blowdown}

Considering the dynamic range of sound level meter $(50$ to $130 \mathrm{~dB})$, the sound pressure level of the main blowdown should be measured at the proper distances from the blowdown so as to avoid "out of range" errors during the measurements. Therefore, measurements are taken at two intervals from its position: $80 \mathrm{~m}$ inside the station and $600 \mathrm{~m}$ outside the station (at the beginning of the residential area near the station).

In the first measurement before gas discharge from the blowdown, the sound pressure level of $76 \mathrm{~dB}$ is recorded (Aweighted). After the gas discharge starts, the main stage of the measurement begins, whose results are presented in Table 1 . The $1 / 3$ octave-band frequency spectrum of the equivalent sound pressure level is shown in Fig. 2 . The noise 
frequency specifications of this figure are used to find practical approaches for noise control of the blowdown. Measurements show the equivalent sound pressure level of $119.4 \mathrm{~dB}$. Also, the maximum sound pressure level of 111 $\mathrm{dB}$ is recorded at a frequency of $1.6 \mathrm{kHz}$. The second measurement is carried out at about $600 \mathrm{~m}$ from the blowdown which is the edge of the surrounding residential area i.e. the worst case scenario for noise pollution. Prior to gas discharge from the blowdown, the sound pressure level of $65 \mathrm{~dB}$ is recorded at this level. The main stage of measurement is fulfilled when gas starts to discharge; the results are given in Table 2. The measurements show the equivalent sound pressure level of $86.6 \mathrm{~dB}$. Also, the maximum sound pressure level of $80 \mathrm{~dB}$ is recorded at a frequency of $800 \mathrm{~Hz}$. The quantities marked as U $50 \mathrm{~dB}$ in the table mean sound levels less than $50 \mathrm{~dB}$ which are out of the dynamic range of the device. Fig. 3 shows the 1/3 octave-band frequency spectrum of the equivalent sound pressure level measured at $600 \mathrm{~m}$ from the main blowdown. Comparison of Figs. 2 and 3 shows the obvious difference between the noise frequency spectra at two different locations i.e. $80 \mathrm{~m}$ and $600 \mathrm{~m}$ from the main blowdown. The most important change is a shift in the frequency of the maximum sound pressure level. The main reason for such frequency shift is the energy dissipation of sound propagation in the free space. Since the acoustic dissipation, scattering effects, and thermoviscosity of air are higher in upper frequencies, the frequency spectrum of the blowdown acoustic field at $600 \mathrm{~m}$ has been displaced towards lower frequencies.

Table 1: Sound Pressure Level Measured At $80 \mathrm{M}$ from the Main Blowdown

\begin{tabular}{|c|c|c|c|c|c|c|c|c|}
\hline \multicolumn{4}{|c|}{ Main Blowdown-Distance: $80 \mathrm{~m}$} & \multirow{17}{*}{ 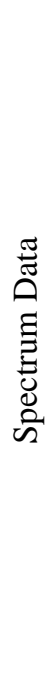 } & $1 / 3$ octave $(\mathrm{Hz})$ & $\mathrm{L}_{\mathrm{eq}}(\mathrm{dB})$ & $1 / 3$ octave $(\mathrm{Hz})$ & $\mathrm{L}_{\mathrm{eq}}(\mathrm{dB})$ \\
\hline \multirow[t]{2}{*}{ Frequency Weighting } & A & \multicolumn{2}{|l|}{$\mathrm{C}$} & & 12.5 & 70.1 & 630 & 107.4 \\
\hline & $\mathrm{dB}$ & \multicolumn{2}{|l|}{$\mathrm{dB}$} & & 16 & 70.9 & 800 & 108.2 \\
\hline $\mathrm{L}_{\mathrm{pk}}$ (MaxP.) & 132.3 & \multicolumn{2}{|l|}{132.3} & & 20 & 71.4 & $1 \mathrm{k}$ & 110.2 \\
\hline \multirow[t]{3}{*}{$\mathrm{L}_{\mathrm{eq}}$} & 119.4 & 120.1 & & & 25 & 73.3 & $1.25 \mathrm{k}$ & 110.9 \\
\hline & & & & & 40 & 74.2 & $2 \mathrm{k}$ & 109.8 \\
\hline & & & & & 50 & 76.7 & $2.5 \mathrm{k}$ & 109.4 \\
\hline \multirow[t]{2}{*}{ Time Weighting } & Slow & Fast & Impulsive & & 63 & 77.9 & $3.15 \mathrm{k}$ & 108.4 \\
\hline & $\mathrm{dB}$ & $\mathrm{dB}$ & $\mathrm{dB}$ & & 80 & 80.8 & $4 \mathrm{k}$ & 106.4 \\
\hline $\mathrm{LA}_{\max }$ & 124.7 & 125.7 & 126.4 & & 100 & 84.2 & $5 \mathrm{k}$ & 103.6 \\
\hline $\mathrm{LA}_{\min }$ & 73.8 & 71.3 & 72.7 & & 125 & 87.3 & $6.3 \mathrm{k}$ & 100.4 \\
\hline $\mathrm{LC}_{\max }$ & 125.4 & 126.2 & 126.7 & & 160 & 89.2 & $8 \mathrm{k}$ & 96.7 \\
\hline $\mathrm{LC}_{\min }$ & 86.5 & 83.7 & 87.8 & & 200 & 92.7 & $10 \mathrm{k}$ & 93.1 \\
\hline Useful Statistics & & & & & 250 & 98.3 & $12.5 \mathrm{k}$ & 89.5 \\
\hline $\mathrm{LA}_{\mathrm{S} 10.0}$ & 122.8 & & & & 315 & 101.3 & $16 \mathrm{k}$ & 85 \\
\hline $\mathrm{LA}_{\mathrm{S} 50.0}$ & 119 & & & & 400 & 102.7 & $20 \mathrm{k}$ & 80.8 \\
\hline $\mathrm{LA}_{\mathrm{S} 90.0}$ & 76.4 & & & & 500 & 104.2 & & \\
\hline
\end{tabular}

Table 2: Sound Pressure Level Measured At $600 \mathrm{M}$ from the Main Blowdown

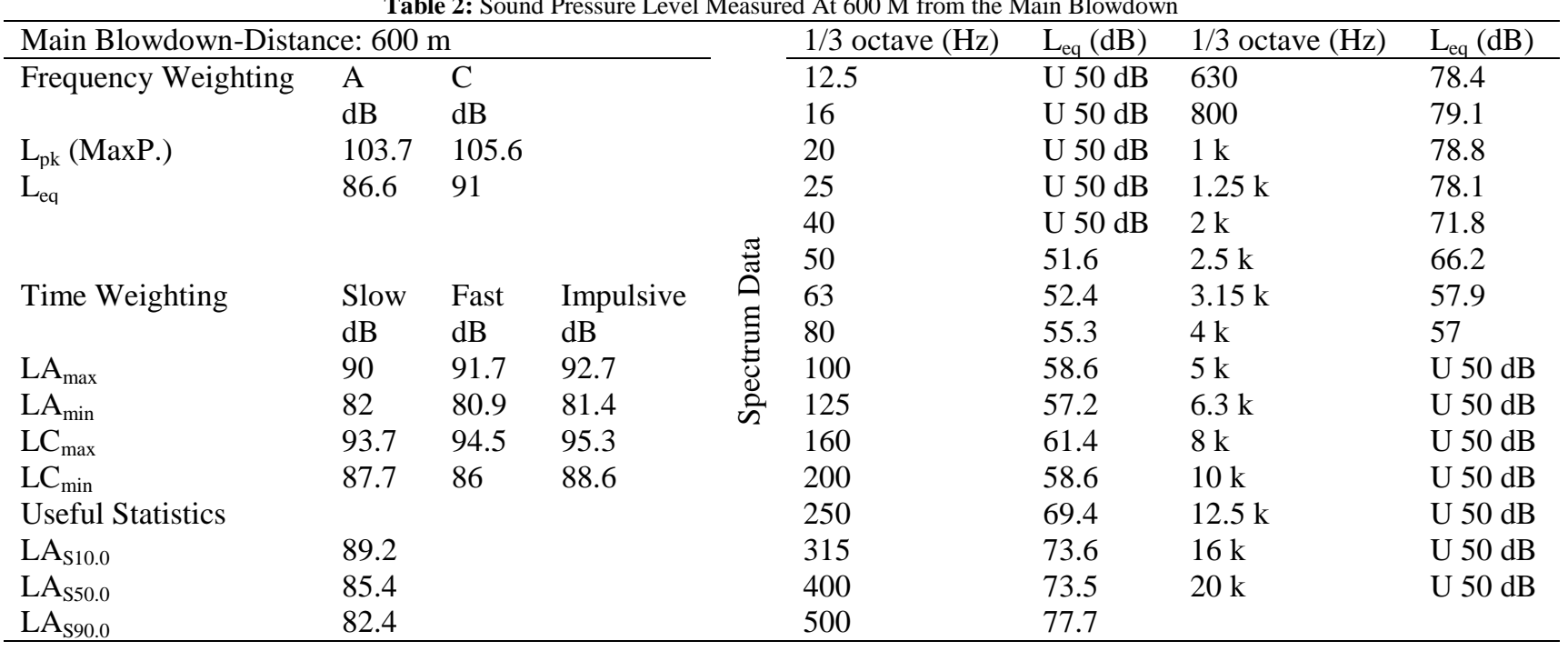




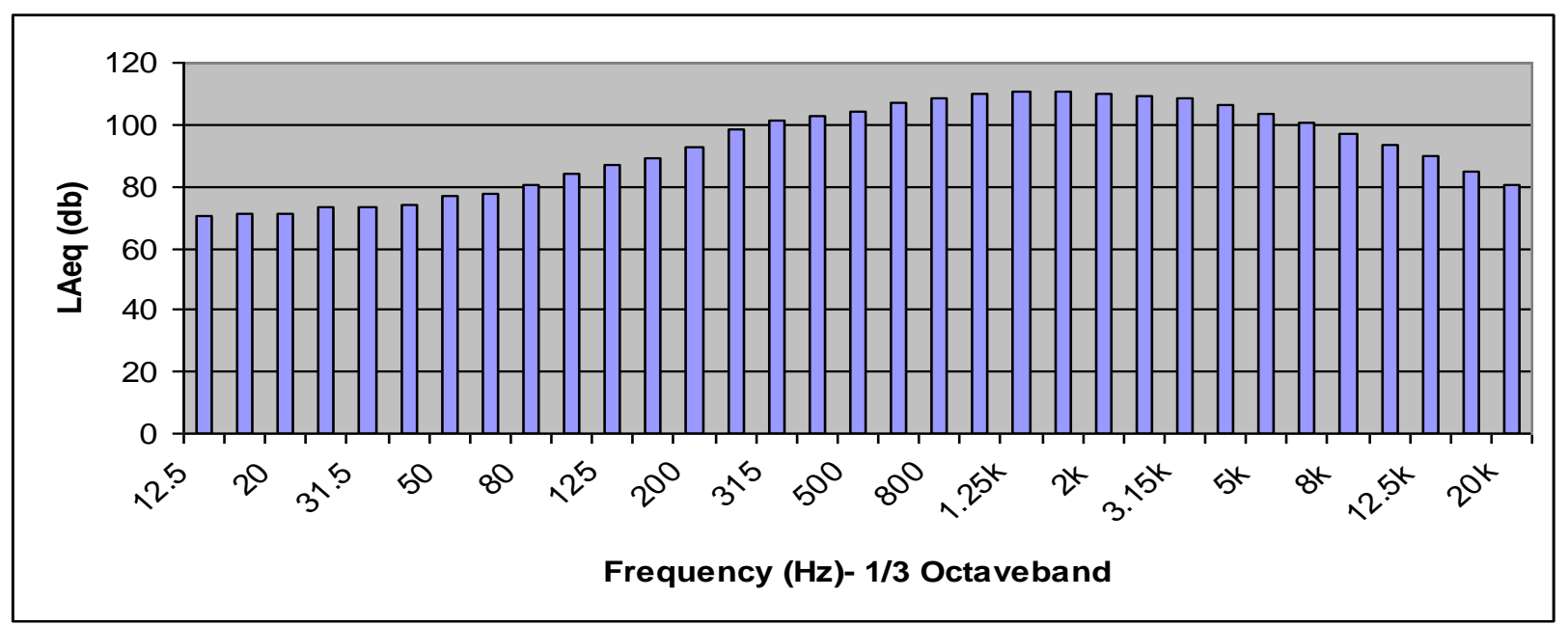

Fig. 2: The 1/3 Octave-Band Frequency Spectrum of the Equivalent Sound Pressure Level Measured at 80 M From the Main Blowdown.

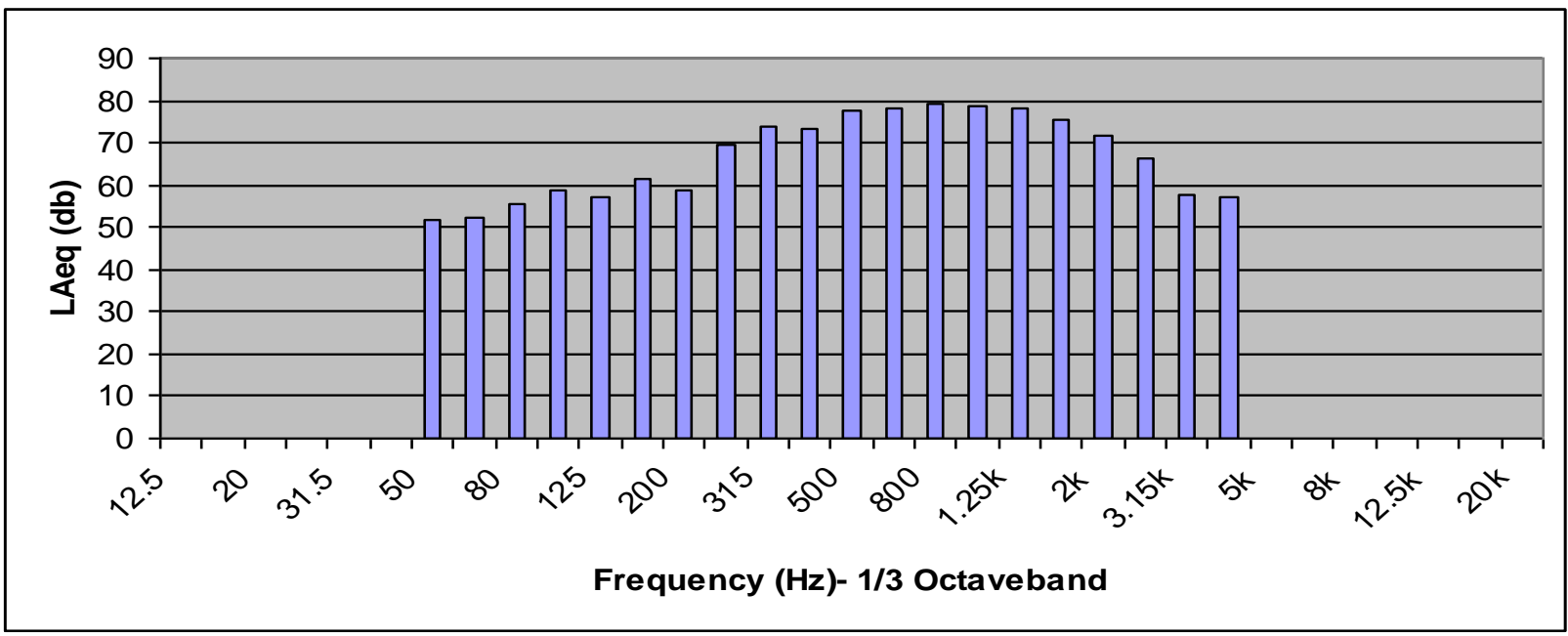

Fig. 3: The 1/3 Octave-Band Frequency Spectrum of the Equivalent Sound Pressure Level Measured at 600 M from the Main Blowdown.

According to noise pollution regulations and standards [1-4], shows a sound pressure level of 86.6 dB at short time intervals of several minutes (up to $1 \mathrm{hr}$ ) will not cause any hearing impairment to the people residing in the surrounding residential areas. However, since the nature of the generated sound is sudden and it sometimes occurs at night, it is quite uncomfortable. Inside the station, on the other hand, the $119.4 \mathrm{~dB}$ sound pressure level indicates that the noise level has exceeded the standard range. When workers are exposed to this noise without any hearing protection devices, they not only experience different physiological impairments, their hearing mechanism can also be injured.

It is worth mentioning that a precise evaluation of the acoustic field caused by the main blowdown is not possible at all the locations inside the station and in the surrounding residential areas because it is not technically possible to repeat the main blowdown tests. Yet, the measurements can be beneficial in estimating the quality and quantity of the acoustic field caused by this blowdown to find practical approaches of noise control.

\subsection{Measuring the sound level of the unit's blowdowns}

To measure the sound pressure level, the blowdown of one of the units is discharged and the sound pressure level is recorded at a point $25 \mathrm{~m}$ from its position. The results along with the $1 / 3$ octave-band frequency spectrum of the equivalent sound pressure level are presented in Table 3 and Fig. 4, respectively. The measurements show the equivalent sound pressure level of $99.9 \mathrm{~dB}$ (A-weighted). Also, the maximum sound pressure level of $93 \mathrm{~dB}$ is recorded at the frequency of $2 \mathrm{kHz}$. It is worth noting that the blowdown's sound pressure level was $87 \mathrm{~dB}$ before the blowdown being discharged.

The frequency spectrum of the sound pressure level (Fig. 4) shows a high frequency acoustic field (similar to the jet noise). Although the sound pressure level of the unit blowdown is less than the main blowdown, but the unit blowdown is discharged several times during the day. Therefore, the units' blowdowns are among the most important sources of noise pollution in the surrounding residential areas. 
Table 3: Sound Pressure Level Measured at $25 \mathrm{M}$ from Unit's Blowdown

\begin{tabular}{|c|c|c|c|c|c|c|c|c|}
\hline \multicolumn{4}{|c|}{ Units Blowdown-Distance: $25 \mathrm{~m}$} & & \multirow{2}{*}{$\begin{array}{l}1 / 3 \text { octave }(\mathrm{Hz}) \\
12.5\end{array}$} & \multirow{2}{*}{$\begin{array}{l}\mathrm{L}_{\mathrm{eq}}(\mathrm{dB}) \\
\mathrm{U} 50 \mathrm{~dB}\end{array}$} & \multirow{2}{*}{$\begin{array}{l}1 / 3 \text { octave }(\mathrm{Hz}) \\
630\end{array}$} & \multirow{2}{*}{$\begin{array}{l}\mathrm{L}_{\mathrm{eq}}(\mathrm{dB}) \\
79.5\end{array}$} \\
\hline \multirow[t]{2}{*}{ Frequency Weighting } & A & \multicolumn{2}{|l|}{$\mathrm{C}$} & \multirow{16}{*}{ 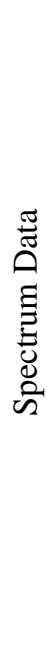 } & & & & \\
\hline & $\mathrm{dB}$ & $\mathrm{dB}$ & & & 16 & $\mathrm{U} 50 \mathrm{~dB}$ & 800 & 83.3 \\
\hline $\mathrm{L}_{\mathrm{pk}}(\mathrm{MaxP})$. & 118.7 & 117.3 & & & 20 & $\mathrm{U} 50 \mathrm{~dB}$ & $1 \mathrm{k}$ & 87.1 \\
\hline \multirow[t]{3}{*}{$\mathrm{L}_{\mathrm{eq}}$} & 99.9 & 99.5 & & & 25 & $\mathrm{U} 50 \mathrm{~dB}$ & $1.25 \mathrm{k}$ & 91.1 \\
\hline & & & & & 40 & $\mathrm{U} 50 \mathrm{~dB}$ & $2 \mathrm{k}$ & 92.8 \\
\hline & & & & & 50 & $\mathrm{U} 50 \mathrm{~dB}$ & $2.5 \mathrm{k}$ & 91.6 \\
\hline \multirow[t]{2}{*}{ Time Weighting } & Slow & Fast & Impulsive & & 63 & $\mathrm{U} 50 \mathrm{~dB}$ & $3.15 \mathrm{k}$ & 90.7 \\
\hline & $\mathrm{dB}$ & $\mathrm{dB}$ & $\mathrm{dB}$ & & 80 & 54 & $4 \mathrm{k}$ & 87.9 \\
\hline $\mathrm{LA}_{\max }$ & 103.7 & 105 & 105.7 & & 100 & 57.7 & $5 \mathrm{k}$ & 84.1 \\
\hline $\mathrm{LA}_{\min }$ & 94.5 & 92.4 & 93.6 & & 125 & 62.3 & $6.3 \mathrm{k}$ & 77.8 \\
\hline $\mathrm{LC}_{\max }$ & 103.1 & 104.3 & 104.9 & & 160 & 65.3 & $8 \mathrm{k}$ & 69.4 \\
\hline $\mathrm{LC}_{\min }$ & 94.8 & 93 & 93.8 & & 200 & 66.8 & $10 \mathrm{k}$ & 59.6 \\
\hline Useful Statistics & & & & & 250 & 72.1 & $12.5 \mathrm{k}$ & $\mathrm{U} 50 \mathrm{~dB}$ \\
\hline $\mathrm{LA}_{\mathrm{S} 10.0}$ & 102.6 & & & & 315 & 74.8 & $16 \mathrm{k}$ & $\mathrm{U} 50 \mathrm{~dB}$ \\
\hline $\mathrm{LA}_{\mathrm{S} 50.0}$ & 99.2 & & & & 400 & 73.9 & $20 \mathrm{k}$ & $\mathrm{U} 50 \mathrm{~dB}$ \\
\hline $\mathrm{LA}_{S 90.0}$ & 94.6 & & & & 500 & 77.6 & & \\
\hline
\end{tabular}

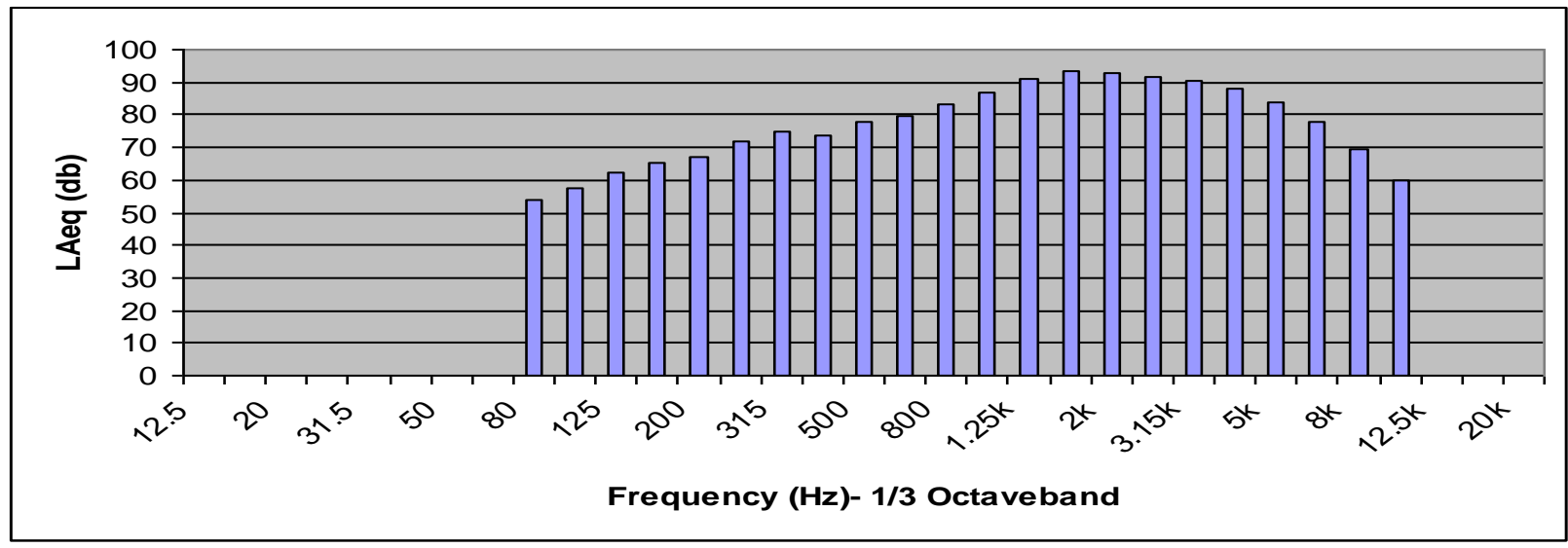

Fig. 4: The 1/3 Octave-Band Frequency Spectrum of the Equivalent Sound Pressure Level Measured at 25

\subsection{Measuring the sound level of the unit's scubbers}

To measure the sound pressure level of unit scrubbers one of them is discharged and the sound pressure level is recorded at a point $40 \mathrm{~m}$ from its position. The measured data is presented in Table 4 and the $1 / 3$ octave-band frequency spectrum of the equivalent sound pressure level is shown in Fig. 5. The measurements show the equivalent sound pressure level of $98.6 \mathrm{~dB}$ (A-weighted). Also, the maximum sound pressure level of $91 \mathrm{~dB}$ is recorded at a frequency of $2 \mathrm{kHz}$. It is should be noted that the scrubber's sound pressure level at the measuring point was $87 \mathrm{~dB}$ before the scrubber being discharged.

Table 4: Sound Pressure Level Measured at $40 \mathrm{M}$ from Unit's Scrubber

\begin{tabular}{|c|c|c|c|c|c|c|c|c|}
\hline \multicolumn{4}{|c|}{ Units Scrubber -Distance: $40 \mathrm{~m}$} & \multirow{2}{*}{\multicolumn{2}{|c|}{$\begin{array}{l}1 / 3 \text { octave }(\mathrm{Hz}) \\
12.5\end{array}$}} & \multirow{2}{*}{$\begin{array}{l}\mathrm{L}_{\mathrm{eq}}(\mathrm{dB}) \\
\mathrm{U} 50 \mathrm{~dB}\end{array}$} & \multirow{2}{*}{$\begin{array}{l}1 / 3 \text { octave }(\mathrm{Hz}) \\
630\end{array}$} & \multirow{2}{*}{$\begin{array}{l}\mathrm{L}_{\mathrm{eq}}(\mathrm{dB}) \\
80.6\end{array}$} \\
\hline Frequency Weighting & $\mathrm{A}$ & $\mathrm{C}$ & & & & & & \\
\hline & $\mathrm{dB}$ & $\mathrm{dB}$ & & & 16 & $\mathrm{U} 50 \mathrm{~dB}$ & 800 & 84.8 \\
\hline $\mathrm{L}_{\mathrm{pk}}(\mathrm{MaxP})$. & 119 & 117.8 & & & 20 & $\mathrm{U} 50 \mathrm{~dB}$ & $1 \mathrm{k}$ & 89 \\
\hline \multirow[t]{3}{*}{$\mathrm{L}_{\mathrm{eq}}$} & 98.6 & 98.3 & & & 25 & $\mathrm{U} 50 \mathrm{~dB}$ & $1.25 \mathrm{k}$ & 90.7 \\
\hline & & & & & 40 & 53 & $2 \mathrm{k}$ & 91.1 \\
\hline & & & & 莺 & 50 & $\mathrm{U} 50 \mathrm{~dB}$ & $2.5 \mathrm{k}$ & 90.5 \\
\hline \multirow[t]{2}{*}{ Time Weighting } & Slow & Fast & Impulsive & $\tilde{\theta}$ & 63 & $\mathrm{U} 50 \mathrm{~dB}$ & $3.15 \mathrm{k}$ & 87.7 \\
\hline & $\mathrm{dB}$ & $\mathrm{dB}$ & $\mathrm{dB}$ & 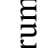 & 80 & 52.9 & $4 \mathrm{k}$ & 83.8 \\
\hline $\mathrm{LA}_{\max }$ & 103.5 & 105.3 & 106.1 & 莺 & 100 & 54.2 & $5 \mathrm{k}$ & 78 \\
\hline $\mathrm{LA}_{\min }$ & 85.7 & 74.2 & 90.3 & $\frac{1}{n}$ & 125 & 56.8 & $6.3 \mathrm{k}$ & 70 \\
\hline $\mathrm{LC}_{\max }$ & 102.9 & 104.8 & 105.3 & & 160 & 55.7 & $8 \mathrm{k}$ & 59.7 \\
\hline $\mathrm{LC}_{\min }$ & 89.8 & 84.2 & 90.8 & & 200 & 56.1 & $10 \mathrm{k}$ & $\mathrm{U} 50 \mathrm{~dB}$ \\
\hline Useful Statistics & & & & & 250 & 61.2 & $12.5 \mathrm{k}$ & $\mathrm{U} 50 \mathrm{~dB}$ \\
\hline $\mathrm{LA}_{\mathrm{S} 10.0}$ & 100.6 & & & & 315 & 64.3 & $16 \mathrm{k}$ & $\mathrm{U} 50 \mathrm{~dB}$ \\
\hline $\mathrm{LA}_{\mathrm{S} 50.0}$ & 98.2 & & & & 400 & 69.7 & $20 \mathrm{k}$ & $\mathrm{U} 50 \mathrm{~dB}$ \\
\hline $\mathrm{LA}_{\mathrm{S} 90.0}$ & 91.2 & & & & 500 & 72.9 & & \\
\hline
\end{tabular}




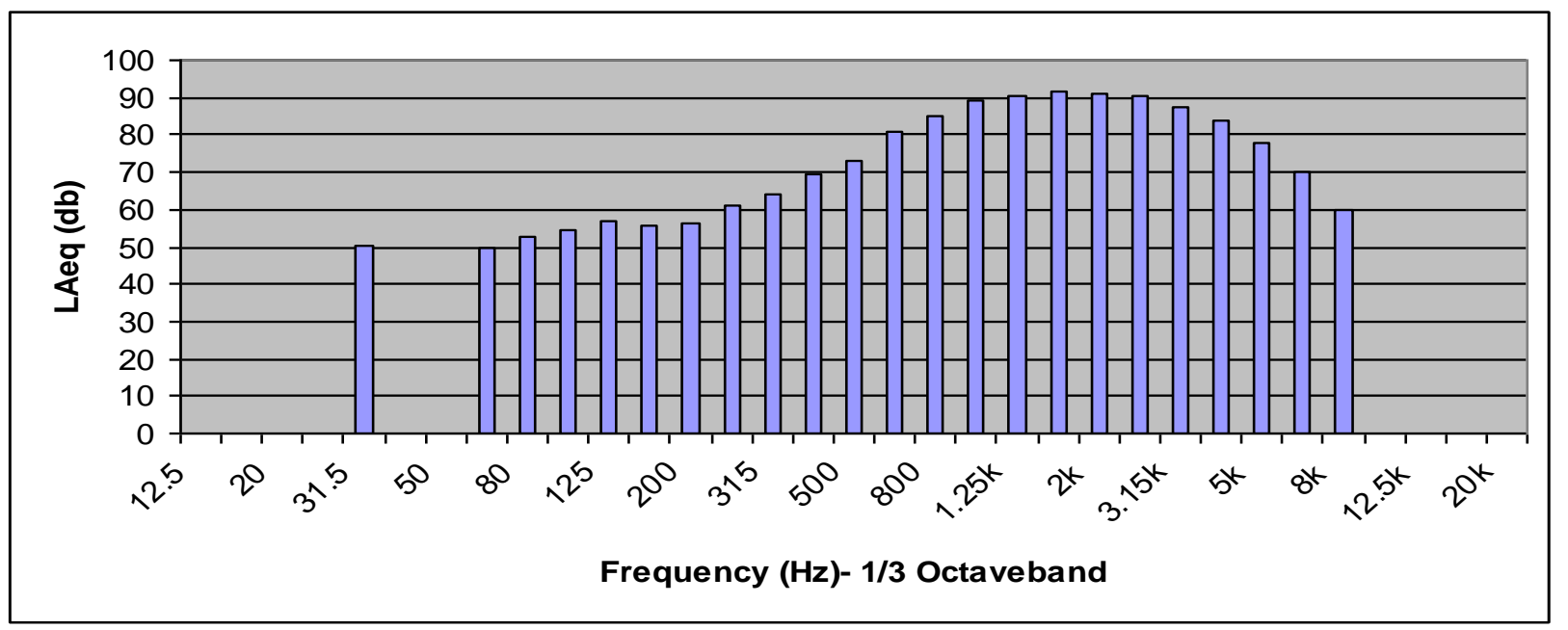

Fig. 5: The 1/3 Octave-Band Frequency Spectrum of the Equivalent Sound Pressure Level Measured at 40 M from Unit's Scrubbers.

\subsection{Measuring the acoustic field around the station}

The sound field caused by the main blowdown, units' blowdowns, and units' scrubbers is generated discontinuously under certain conditions; Therefore, the noise pollution, to which the station workers and the people residing in the surrounding residential areas are continually exposed, is the one caused by 4 turbo-compressor units in the station's line 2. During the day, this noise field is negligible compared to the background noise field caused by the vehicles traffic around the station and to the existing general noise. At night, however, it could be a nuisance. For the worst case scenario at the beginning of the residential area near the station, the sound pressure level has been recorded as $65 \mathrm{~dB}$. According to the noise pollution regulations and standards [1-4], the maximum allowable values of the sound pressure level for residential areas are 45 and $55 \mathrm{~dB}$ for nights and days, respectively. Although a sound pressure level of $65 \mathrm{~dB}$ cannot cause hearing impairment, exceeding the allowable values by $10-20 \mathrm{~dB}$ can be a cause of annoyance and dissatisfaction of the residing people. Therefore, the analysis of the acoustic field generated by the set of turbocompressors and their gas transfer piping is quite important.

Dividing the turbo-compressors set of unit 4 into different zones and measuring the sound pressure level in each zone, the noise map of the set including the isosonic lines is obtained using the meshing and data interpolation technique of Surfer and MATLAB software (see Fig. 6). It is clear that the sound pressure level increases as colors vary from cold to warm. As it is shown in the noise map, the sound pressure level inside the turbo-compressors set next to the turbine is $117 \mathrm{~dB}$ which indicates the critical condition for noise pollution. Also, the sound pressure level around the unit's inlet gas pipe is about $105 \mathrm{~dB}$ which is somewhat due to the acoustic leakage of the gas transfer pipe. The inlet and outlet gas pipes are not equipped with proper insulation .In addition; the protective enclosure around the set of turbo-compressors has been built with a single layer of steel without any appropriate acoustic insulation. In the design and installation phase of turbo-compressors set, the necessary acoustic insulation was not considered. This, in turn, causes the sound field to propagate outside the turbo compressors and, hence, inside the station and to the surrounding residential areas. Considering the sound pressure level around the set of turbo-compressors, all the regions inside and around the set are lying in the dangerous acoustic zone (sound level above $85 \mathrm{~dB}$ ), and if the related personnel work there without any standard hearing protection devices, their hearing will impair in the long term.

\subsection{Measuring the acoustic field around the station}

Control rooms are located next and parallel to the units. This situation along with the rock hills behind the rooms that are working as sound reflector significantly intensifies the sound pressure level inside the control rooms. The problem has been resolved mostly through double glazed windows and insulation. Measurements of the sound pressure level inside the control rooms are done while units 2 and 4 are running. The sound pressure level inside the rooms was measured to be around $60 \mathrm{~dB}$. Using double glazed windows and insulation cause a noise reduction of about $20 \mathrm{~dB}$. For administrative offices, a sound pressure level of $60 \mathrm{~dB}$ is accepted according to international standards, but when all 4 units are working simultaneously under full loading conditions, the sound pressure level is close to $60+60 \equiv 63 \mathrm{~dB}$ which is higher. However, since the personnel work on shifts, their permanent hearing impartment is out of question, yet such physiological effects as nervousness, disordered asleep and so on are quite probable. 


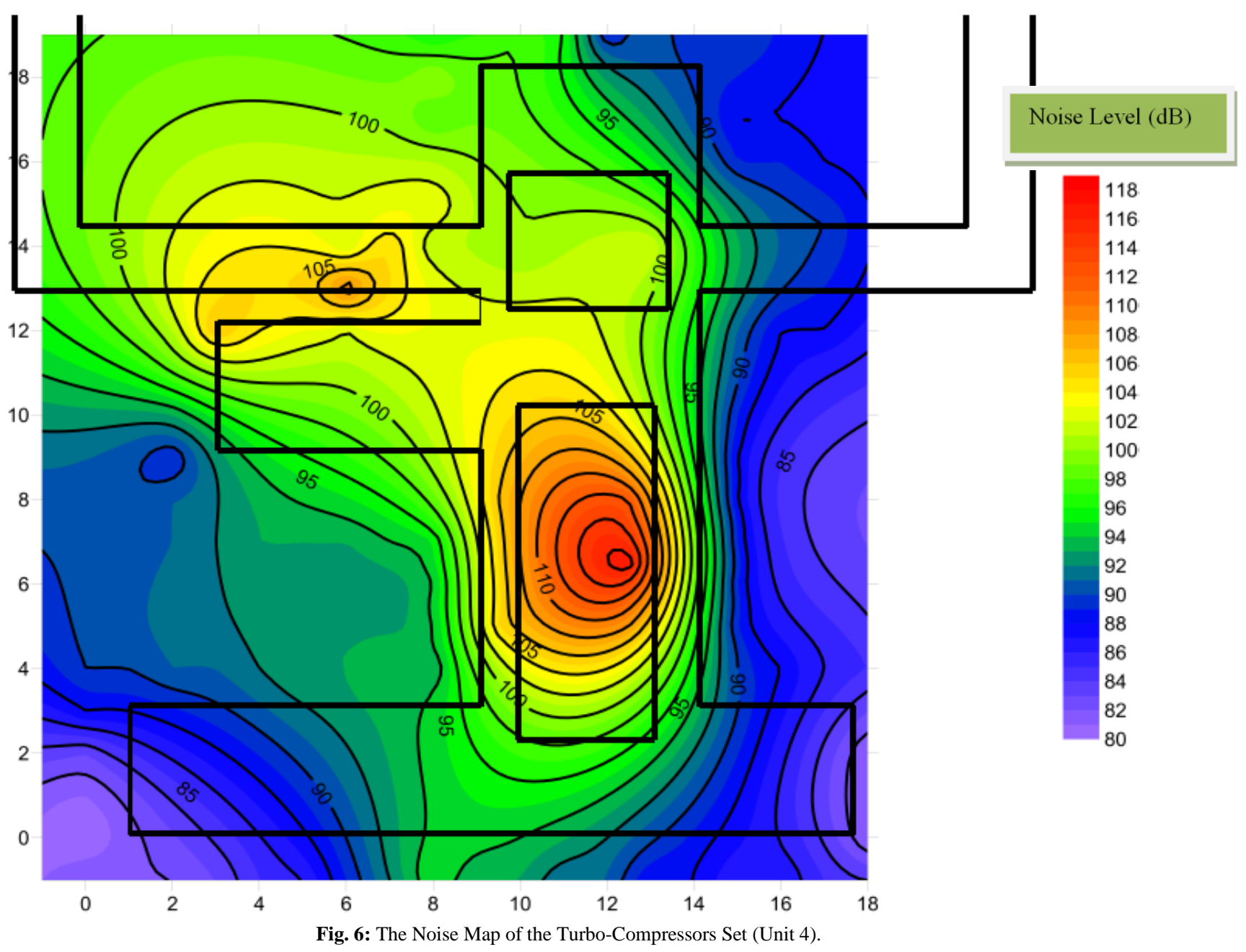

\section{Prioritization of the station's noise sources}

Technical analysis of the measured data results in the following prioritization for the noise sources of the station line 2:

1) The main blowdown

2) The units' scrubbers

3) The units' blowdowns

4) The set of turbo-compressors

5) The pipes that transfer gas from/to the turbo-compressors

In fact, if we consider how many times these units are running along with the harmful effects they could have on the residing people's nervous system, prioritization of the noise sources is somewhat different as follows:

1) Units' blowdowns

2) The main blowdown

3) Units'scrubbers

4) The set of turbo-compressors

5) The pipes that transfer gas from/to the turbo-compressors

The noise control of the each element needs a thorough investigation and an appropriate remediation. The approach should be proposed based on the acoustic field of the equipment, their frequencies and engineering specifications such as the blowdowns' and scrubbers' geometries, their constituting materials, connections, and the physics of the sound propagation in the site of interest. 


\section{Conclusion}

The study of noise condition in the Noor-Abad gas compressor station shows that the major noise sources are respectively main and unit's blowdowns, unit's scrubbers, turbo-compressors and gas transfer pipes. For primary blowdown, the maximum sound pressure level of $111 \mathrm{dBA}$ at $1.6 \mathrm{kHz}$ and $80 \mathrm{dBA}$ at $800 \mathrm{~Hz}$ are recorded for two critical points i.e. $80 \mathrm{~m}$ inside the station and $600 \mathrm{~m}$ the edge of residential area, respectively. The pressure levels for secondary blowdown, $25 \mathrm{~m}$ away from its position, and for scrubber at $40 \mathrm{~m}$ interval are $93 \mathrm{dBA}$ and $91 \mathrm{dBA}$ at the same frequency of $2 \mathrm{kHz}$. However, if we take into account the running times of these units per day as well as their harmful effects on an individual's nervous system, unit's blowdowns could be considered as the first noise source.

\section{References}

[1] H. Lewis, Industrial Noise Control, Fundamentals and Applications, Bell and associates. MARCEL DEKKER, INC. New York and Basel, (1962).

[2] P. N. Cheremisinoff and P. P. Cheremisinoff, Industrial Noise Control Handbook, ANN ARBOR Science Publishers INC., (1977).

[3] L. L. Beranek, Noise and Vibration Control, McGraw Hill, (1971).

[4] C. J. Hemond, Engineering Acoustics and Noise Control, Englewood cliffs, New Jersey, (1983).

[5] Acoustics-Determination of occupational noise exposure-Engineering method, International Standard ISO 9612, (2009).

[6] Acoustics-Description and measurement of environmental noise-Part 1: Basic Quantities and Procedures, International Standard ISO 1996/7, (1982).

[7] Acoustics-Specification for sound level meters, IEC 60651, (1979).

[8] Electroacoustics-Octave-band and fractional-octave-band filters, IEC 61260, (2014).

[9] Acoustics-Acoustic calibrator, IEC 942 (Class 2), (1988).

[10] Acoustics-Noise emitted by machinery and equipment-Determination of emission sound pressure levels at a work station and at other specified positions in an essentially free field over a reflecting plane with negligible environmental corrections, International Standard ISO 11201, (2010) 